\title{
TEMPERATURA CRÍTICA MÁXIMA DE DUAS ESPÉCIES DE CAMARÕES DULCÍCOLAS SINTÓPICAS NO RIO DA MATA, IGRAPIÚNA, BAHIA, BRASIL
}

\author{
Novais, W.R.R. ${ }^{1,}$; Soares-Silva, A.C. ${ }^{1}$; Carilo Filho, L.M. ${ }^{2}$; Costa, R.N. ${ }^{2}$ \& Mira-Mendes, C.V. ${ }^{2}$ \\ ${ }^{1}$ Universidade Estadual de Santa Cruz, Campus Soane Nazaré de Andrade, Laboratório de Ecologia Bêntica, Grupo \\ de Pesquisa em Carcinologia e Biodiversidade Aquática (GPCBio). \\ ${ }^{2}$ Universidade Estadual de Santa Cruz, Campus Soane Nazaré de Andrade. Laboratório de Herpetologia. \\ *Autor correspondente: wrrnovais@uesc.br
}

\begin{abstract}
A temperatura crítica máxima (CTmax) é uma importante ferramenta ecofisiológica que permite avaliar a resposta de organismos ao estresse térmico. O presente estudo teve como objetivo avaliar a tolerância térmica de duas espécies de camarão sintópicas em um trecho do Rio da Mata $\left(13^{\circ} 49^{\prime} 43.5^{\prime \prime} \mathrm{S}, 39^{\circ} 10^{\prime} 28.7^{\prime \prime} \mathrm{W}\right)$, localizado na Reserva Ecológica Michellin, município de Igrapiúna, estado da Bahia, Brasil. Foram coletados 28 indivíduos de Potimirim potimirim (Müller, 1881) e 15 indivíduos de Macrobrachium olfersii Wiegmann, 1836. A temperatura nictimeral foi obtida por meio da instalação de datalogger junto à margem do rio. O perfil térmico diário foi obtido a partir de registros de temperatura em intervalos 15 minutos. Uma vez em laboratório os camarões foram aclimatados a $24{ }^{\circ} \mathrm{C}$ durante 48 horas em fotoperíodo de 12 horas (claro-escuro). Na aclimatação foram utilizados recipientes com 4,5 litros de água captada do mesmo rio em que foram coletados os indivíduos. O experimento foi realizado no interior de um sistema de aquecimento homogêneo onde foram distribuídas as câmaras experimentais (recipientes de $400 \mathrm{ml}$ com água do mesmo rio em que foram coletados os espécimes). O experimento iniciou-se à temperatura inicial de $24{ }^{\circ} \mathrm{C}$ com o subsequente aquecimento à uma taxa gradual e constante de $0,3{ }^{\circ} \mathrm{C} / \mathrm{min}$. Os camarões tiveram seus reflexos testados periodicamente por meio de estímulos mecânicos com o auxílio de uma pinça e admitidos como em CTmax quando apresentavam total desequilíbrio, desorientação ou ausência de resposta ao estímulo. Ao atingirem a CTmax, a temperatura da água da respectiva câmara experimental foi aferida com termômetro de leitura rápida (precisão de $0,1{ }^{\circ} \mathrm{C}$ ), o camarão retirado e imediatamente submetido ao resfriamento em $24{ }^{\circ} \mathrm{C}$, e então mantidos em observação por 24 horas. Apenas os dados dos indivíduos que sobreviveram foram utilizados nas análises, os mesmos foram então eutanasiados e tiveram então o comprimento do cefalotórax (CC) mensurado. A CTmax média registrada foi de 36,27 $\pm 0,15$ ${ }^{\circ} \mathrm{C}(34,4-37,3)$ para $P$. potimirim e $36,52 \pm 0,21{ }^{\circ} \mathrm{C}(35,4-37,6)$ para M. olfersii. A temperatura média da água registrada para o local de coleta foi de $23,2 \pm 0,04{ }^{\circ} \mathrm{C}(22,52-23,77)$. Houve uma correlação negativa entre a CTmax e o CC para P. potimirim ( $r h o=-0,75 ; p<0,01$ ), enquanto para $M$. olfersii não houve relação significativa ( $r h o=-0,30 ; p=0,28)$. Não foi encontrada diferença significativa ( $\mathrm{t}=0,97 ; p=0,34)$ entre a CTmax das espécies estudadas.
\end{abstract}

Palavras-chave: CTmax, Atyidae, Palaemonidae, água doce, tolerância ao calor. 